\title{
Fractionated Concurrent Exercise throughout the Day Does Not Promote Acute Blood Pressure Benefits in Hypertensive Middle-aged Women
}

\author{
Luan M. Azevêdo ${ }^{1 *}$, Alice C. de Souza', Laiza Ellen S. Santos', Rodrigo Miguel dos Santos', \\ Manuella O. M. de Fernandes ${ }^{1}$, Jeeser A. Almeida ${ }^{2}$ and Emerson Pardono ${ }^{1}$

\begin{abstract}
'Programa de Pós Graduação em Educação Física (PPGEF), Universidade Federal de Sergipe, São Cristóvão, Brazil, ${ }^{2}$ Programa de Pós Graduação em Saúde e Desenvolvimento na Região Centro-Oeste (PPGSD), Universidade Federal de Mato Grosso do Sul, Campo Grande, Brazil
\end{abstract}

\section{OPEN ACCESS}

Edited by:

Teresa Maria Seccia,

University of Padova, Italy

Reviewed by:

Marzena Chrostowska,

Medical University of Gdansk, Poland

Yuko Gando,

National Institutes of

Biomedical Innovation, Health

and Nutrition, Japan

*Correspondence:

Luan M. Azevêdo

luan.azvdo@gmail.com

Specialty section: This article was submitted

to Hypertension,

a section of the journal

Frontiers in Cardiovascular Medicine

Received: 15 September 2016 Accepted: 25 January 2017

Published: 14 February 2017

Citation:

Azevêdo LM, Souza AC, Santos LES, Miguel dos Santos R, Fernandes MO, Almeida JA and Pardono E (2017)

Fractionated Concurrent Exercise throughout the Day Does Not

Promote Acute Blood Pressure Benefits in Hypertensive Middle-aged

Women.

Front. Cardiovasc. Med. 4:6 doi: 10.3389/fcvm.2017.00006
Hypertension is a chronic disease that affects about $30 \%$ of the world's population, and the physical exercise plays an important role on its non-pharmacological treatment. Anywise, the dose-response of physical exercise fractionation throughout the day demands more investigation, allowing new exercise prescription possibilities. Therefore, this study aimed to analyze the acute blood pressure (BP) kinetics after $1 \mathrm{~h}$ of exercises and the BP reactivity after different concurrent exercise (CE) sessions and its fractioning of hypertensive middle-aged women. In this way, 11 hypertensive women voluntarily underwent three experimental sessions and one control day [control session (CS)]. In the morning session (MS) and night session (NS), the exercise was fully realized in the morning and evening, respectively. For the fractionized session (FS), 50\% of the volume was applied in the morning and the remaining 50\% during the evening. The MS provided the greatest moments $(p \leq 0.05)$ of post-exercise hypotension (PEH) for systolic BP (SBP) and highest reduction of BP reactivity for SBP ( 44\%) and diastolic $\mathrm{BP}$ (DBP) ( 59\%) compared to CS ( $p \leq 0.05)$. The findings of the present study have shown that MS is effective for $\mathrm{PEH}$ to SBP, as well as it promotes high quality of attenuation for $\mathrm{BP}$ reactivity, greater than the other sessions.

Keywords: systemic arterial hypertension, cardiovascular diseases, combined exercise, post-exercise hypotension, cardioprotection

\section{INTRODUCTION}

World data have shown that systemic arterial hypertension (SAH) has one of the largest number of occurrences (about 30\%), and it was indirectly responsible for about 9.4 million deaths in $2010(1-3)$. The SAH is understood as a clinical condition caused by multiple factors, showing high and sustained levels of blood pressure (BP) for systolic (SBP $\geq 140 \mathrm{mmHg}$ ) and/or diastolic (DBP $\geq 90 \mathrm{mmHg}$ ).

Abbreviations: 8-RM, eight repetition maximum test; ACSM, American College of Sports Medicine; AE, aerobic exercise; $\mathrm{BMI}$, body mass index; $\mathrm{BP}$, blood pressure; $\mathrm{CE}$, concurrent exercise; $\mathrm{CPT}$, cold pressor test; $\mathrm{CS}$, control session; $\mathrm{DBP}$, diastolic blood pressure; DP, double product; FS, fractionized session; HC, hip circumference; HR, heart rate; ICC, intraclass correlation coefficient; MAP, mean arterial pressure; MS, morning session; NS, night session; PEH, post-exercise hypotension; RE, resistance exercise; SAH, systemic arterial hypertension; SBP, systolic blood pressure; SPE, subjective perception of effort; WC, waist circumference; WHO, World Health Organization; WHR, waist-hip ratio. 
There are some possibilities for $\mathrm{SAH}$ treatment, including non-pharmacological therapy. It includes changes in behavioral factors, among which physical exercise presents one of the most effective and safe intervention (4). The acute benefits after exercise include post-exercise hypotension $(\mathrm{PEH})$ and the attenuation of $\mathrm{BP}$ reactivity, as the morphological and functional adaptations when realized chronically, increasing the basal metabolism and the reduction of the rest $\mathrm{BP}$ values (5-7).

Post-exercisehypotension is termed by the post-exercise period in which are registered lower BP values than those measured in the pre-exercise or in a control day $(8,9)$. This phenomenon has great clinical relevance (10-12) and has been shown for normotensive (13), pre-hypertensive (14), and hypertensive (15) individuals, and it can be observed during the $24 \mathrm{~h}$ following the exercise $(14,16)$. These BP decay ranged approximately $-3.5 /-2.5 \mathrm{mmHg}$ after aerobic exercise (AE) and $-1.8 /-3.2 \mathrm{mmHg}$ after dynamic resistance exercise (RE) (6), and the most important, it is enough to decrease by $4 \%$ of overall risk of mortality caused by coronary diseases (17).

Some studies (18-20) suggested that AE may be prioritized in the prescription programs for hypertensive individuals since it promotes better $\mathrm{PEH}$ than RE (18). However, the effect of $\mathrm{AE}$ and RE combination in the same session or even on separate days [concurrent exercise (CE)] $(19,21)$ has also been studied.

Since 2004, many studies have analyzed the BP kinetics after CE $(18,22-30)$, but only five of them were conducted with elderly population (22, 23, 27-29). Additionally, just few researchers evaluated this response at different day shifts (31-34) and have examined the fractionation volume of a workout session, performing it throughout the day (14, 35-39).

To the best of our knowledge, this was the first study to investigate the effect of a CE session performed in the morning, evening, and fractionated sessions (50\% in the morning and the other $50 \%$ at night) and evaluating the acute BP kinetics and its reactivity after sessions in hypertensive middle-aged women. Therefore, this study aimed to analyze the acute BP kinetics after $1 \mathrm{~h}$ of exercises and the BP reactivity after different $\mathrm{CE}$ sessions and its fractioning of hypertensive middle-aged women. The hypothesis of our study was that the CE session fractionized throughout the day would promote better $\mathrm{PEH}$ than the other sessions.

\section{MATERIALS AND METHODS}

\section{Experimental Approach to the Problem}

All sessions, exercise, and control were performed in common time for all volunteers (08:00 $\mathrm{h}$ and 18:00 h), as well as randomized and with a minimum interval of $72 \mathrm{~h}$ between each, to obtain uniformity and minimize bias that could influence BP kinetics regarding the different day times. Moreover, all experimental sessions were conducted by three qualified professionals, yielding a ratio of 3:2 (professional:participant) at all times during the study.

The volunteers were instructed to maintain a moderate rate of movement during the RE ( $2 \mathrm{~s}$ for the concentric phase and $2 \mathrm{~s}$ for the eccentric phase), breathing freely to avoid Valsalva maneuver and ingest water ad libitum during all sessions. Additionally, the intake of foods/drinks containing caffeine was not suspended, because some studies (40-42) have shown that suspending the chronic use of this substance leads to various side effects that could affect our results, besides causing possible discomfort to volunteers.

\section{Subjects}

Eleven hypertensive middle-aged women $(57.5 \pm 5.1$ years $)$ voluntarily participated of this study and had at least 3 months of CE experience. The anthropometric and hemodynamics characteristics of the study group are presented in Table 1; no differences were detected between the rest values over the days of sessions.

The present study has been approved by the Research Ethics Committee of Federal University of Sergipe (CAAE: 49154515.2.0000.5546) and followed the norms advocated by the Declaration of Helsinki (43). Additionally, all volunteers have signed an Informed Consent Form.

\section{Procedures}

\section{Anthropometric Assessment}

The body mass $(\mathrm{kg})$ and height $(\mathrm{cm})$ of all volunteers were obtained using an anthropometric balance (Welmy SA, Santa Barbara do Oeste, Brazil), with a maximum capacity of $150 \mathrm{~kg}$, and $0.1 \mathrm{~kg}$ of scale. From these two variables, the body mass index (BMI) was estimated.

Subsequently, the abdominal circumference (AC), waist circumference (WC), and hip circumference (HC) were measured using an anthropometric metal tape (Sanny, São Bernardo do Campo, Brazil) with $0.1 \mathrm{~mm}$ scale. With these values, the waisthip ratio of all volunteers was estimated. All measurements were made following the World Health Organization protocol (44).

\section{Subjective Perception of Effort (SPE)}

The intensity of the exercises was estimated and controlled using the SPE of each participant, which was obtained from the visual analog scale OMNI-GSE (45). This instrument has high reliability in obtaining this variable, especially because it has facial

TABLE 1 | Anthropometric and hemodynamics characteristics of the study sample $(n=11)$.

\begin{tabular}{lcc}
\hline & Mean \pm SD & Cl (95\%) \\
\hline Anthropometrics & & \\
Age (years) & $57.5 \pm 5.1$ & $54.0-60.9$ \\
Body mass $(\mathrm{kg})$ & $70.1 \pm 10.6$ & $62.9-77.2$ \\
Height $(\mathrm{m})$ & $1.5 \pm 0.6$ & $1.5-1.6$ \\
BMl $\left(\mathrm{kg} / \mathrm{m}^{2}\right)$ & $30.7 \pm 3.9$ & $28.1-33.4$ \\
AC $(\mathrm{cm})$ & $98.8 \pm 12.2$ & $90.5-107.0$ \\
WC $(\mathrm{cm})$ & $90.4 \pm 11.9$ & $82.4-98.3$ \\
HC $(\mathrm{cm})$ & $102.4 \pm 9.3$ & $95.8-109.1$ \\
WHR & $0.9 \pm 0.1$ & $0.8-1.0$ \\
Hemodynamics & & \\
SBP $(\mathrm{mmHg})$ & $121 \pm 6.4$ & $117-125$ \\
DBP (mmHg) & $75 \pm 7.1$ & $70-80$ \\
MAP (mmHg) & $89 \pm 7.0$ & $84-94$ \\
HR (bpm) & $70 \pm 8.6$ & $64-76$ \\
DP (mmHg $\times$ bpm) & $8,404 \pm 975.2$ & $7,749-9,059$ \\
\hline
\end{tabular}

$B M I$, body mass index; AC, abdominal circumference; WC, waist circumference; $H C$, hip circumference; WHR, waist/hip ratio; SBP, systolic blood pressure; DBP, diastolic blood pressure; MAP, mean arterial pressure; HR, heart rate; DP, double product. ${ }^{a} A l l$ volunteers were under antihypertensive treatment. 
expressions attached to the scale (score $0-10$ ), that help recognize the effort that the individual is performing.

\section{Eight Repetition Maximum Test (8-RM)}

After three familiarization sessions with the exercises and following the proposed protocol, the volunteers underwent a test for estimation of the maximum loads, applied in 2 days and with a $72 \mathrm{~h}$ minimum interval between each of them. This interval allows to obtain greater reliability and reproducibility of results $(46,47)$. The reproducibility was estimated from the analysis of the intraclass correlation coefficient (ICC) between these two measures, adopting an ICC $\geq 0.90$ as acceptable.

This test consisted in an execution of eight maximum repetitions (48), after preheating $(1 \times 10$ repetitions at $50 \%$ load used in familiarization). The volunteer could not perform the ninth repetition, or either self-reported an SPE $\geq 9$ and/or neuromuscular fatigue (inability to sustain the cadence of the movement). The load used to achieve this fatigue was adopted as the maximum load of each volunteer (100\%), from which $75 \%$ of it was calculated to be used in the experimental protocols described later.

Each volunteer performed three attempts for the following exercises: Leg Press, Machine Row, Deadlift, and Bench Press, with a two to five rest-minutes period between them. These exercises were performed in alternating body segments order to facilitate recovery and minimize fatigue. It is noteworthy that prior standardized instructions and verbal encouragement were given in order to obtain results as close as possible to their maximum (49).

\section{BP and BP Reactivity Assessment}

All BP measurements were performed on the left arm having the volunteer comfortably sat in a quiet room at the controlled temperature of $25^{\circ} \mathrm{C}$, using an automatic, calibrated and validated device (Microlife, model BP 3AC1-1) (50), by which it was obtained: systolic blood pressure (SBP), diastolic blood pressure (DBP), and heart rate.

Once the volunteers arrived at the laboratory, they were instructed to sit, and the BP was measured over $20 \mathrm{~min}$, measuring the $\mathrm{BP}$ each $5 \mathrm{~min}$ in order to get the arithmetic mean of $\mathrm{BP}$ at rest. After this period, the sessions were conducted.

At the end of each session, the volunteers were led to a rest room in the laboratory, and they were instructed to remain sat for $1 \mathrm{~h}$. During this time, the BP was measured every $15 \mathrm{~min}$ (Rec15, Rec30, Rec45, and Rec60). Finally, the volunteers underwent the cold pressor test (CPT) to analyze the BP reactivity.

The $\mathrm{BP}$ reactivity is a hemodynamic variable characterized by sudden BP increase after a stressful event of physical or psychological nature, and some studies involving physical exercise (7, 51) emulate such circumstances by applying a procedure known as $\mathrm{CPT}$. The CPT consists on submerging one hand in ice water $\left(\sim 4^{\circ} \mathrm{C}\right)$, measuring up the $\mathrm{BP}$ in the contralateral arm immediately after $1 \mathrm{~min}$ of this submersion, as described by Hines and Brown (52).

\section{Morning and Night Exercise Sessions}

The morning and night sessions consisted of three sets of 10 repetitions $(3 \times 10$ at $75 \%$ of 8 -RM) with active rest between sets
( 1 min of moderate walk at 5-6 SPE scale), since this recover is suggested to enhance the PEH (53). The following exercises were Leg Press, Machine Row, Deadlift, and Bench Press. After the RE, the volunteers performed the AE (20 min of moderate-to-severe cycling at 7-8 SPE scale). The control session was conducted under the same conditions of this experimental session, with the exception that the subjects did not perform exercises.

\section{Fractionized Exercise Session}

The fractionized session (FS) was performed by the fragmentation of the proposed exercises before described. Thus, the volunteers reported to the laboratory in both shifts, in the morning (0800 hours) and at night (1800 hours) of the same day.

Once the volunteers arrived in the morning, the $\mathrm{BP}$ at rest was measured following the procedures described previously. After that, they performed three sets of 10 repetitions $(3 \times 10$ at $75 \%$ of $8-\mathrm{RM})$ in the Leg Press and Machine Row, with active rest between sets ( 1 min of moderate walk at 5-6 SPE scale), plus 10 min of cycling at moderate-severe intensity (at 7-8 SPE scale). Subsequently, the volunteers were released to their respective daily activities.

When the volunteers returned to the laboratory at night, they performed three sets of 10 repetitions $(3 \times 10$ at $75 \%$ of $8-\mathrm{RM})$ in the Deadlift and Bench Press, with active rest between sets ( 1 min of moderate walk at 5-6 SPE scale), plus 10 min of cycling at moderate-severe intensity (at 7-8 SPE scale). After these procedures, the volunteers were conducted to the rest room to record BP of $1 \mathrm{~h}$ post-exercise, and then they underwent the CPT.

\section{Statistical Analysis}

The results were expressed using elements of descriptive statistics (mean, SD, absolute and relative frequencies) for all values obtained. Data normality was tested from the Shapiro-Wilk test and the homogeneity by the Levene test.

Analysis of variance with repeated measures was used to compare the delta variations $\left[\mathrm{BP}_{\text {rest }}-(\operatorname{Rec} 15\right.$ or $\operatorname{Rec} 30$ or Rec 45 or Rec60 or CPT)], adjusting for the main effect of Bonferroni. As for possible differences between sessions, the analysis of covariance, with multiple comparisons between pairs of Bonferroni, was applied.

All analyses were adjusted from the inclusion of antihypertensive drugs categorized as dichotomous covariates (54), as well the cardiovascular risk factors, such as BMI and menopause status in their respective categories, and smoking, diabetes, and hypercholesterolemia also as dichotomous covariates.

The power of the sample size was calculated using the $\mathrm{G}^{\star}$ Power, version 3.1.9.2 (Erdfelder, Faul, \& Buchner, 1996, Kiel, Germany), considering the sample size of this study and $\alpha=0.05$, obtaining a statistical power $(1-\beta)$ of 0.96 for the performed analysis. The data were analyzed using SSPSS (Version 22.0; IBM Corp., Armonk, NY, USA), adopting a significance level of 5\% $(p=0.05)$.

\section{RESULTS}

Figure 1 shows the SBP delta variations obtained in each postexercise moments and at the control day. Reductions were 
observed $(p \leq 0.05)$ in $\operatorname{Rec} 15(-7.1 \pm 12.1$ vs. $5.6 \pm 8.7 \mathrm{mmHg})$, $\operatorname{Rec} 45(-10.7 \pm 12.9$ vs. $4.9 \pm 8.8 \mathrm{mmHg})$, and Rec60 ( $-6.8 \pm 11.5$ vs. $\pm 7.3 \pm 11.6 \mathrm{mmHg}$ ) moments when comparing morning session (MS) to control session (CS), and at the Rec45 (-10.7 \pm 12.9 vs. $3.3 \pm 9.5 \mathrm{mmHg}$ ) when MS was compared to FS. By analyzing the night session (NS), differences were found $(p \leq 0.05)$ only between $\operatorname{Rec} 15(-6.6 \pm 7.7$ vs. $5.6 \pm 8.7 \mathrm{mmHg})$ and Rec45 $(-6.3 \pm 5.1$ vs. $4.9 \pm 8.8 \mathrm{mmHg})$ moments compared to CS.

Figure 2 presents the range of DBP expressed in the postexercise moments. An atypical increase of BP occurred starting at Rec30 of NS $(-1.5 \pm 4.4$ to $2.3 \pm 4.2 \mathrm{mmHg})$; however, no differences were observed between sessions.

The percentage of variance from the acute response after CPT, taking CS as reference, is presented in Table 2 . Only MS provided significant attenuation of the $\mathrm{BP}$ reactivity $(p \leq 0.05)$ compared to the CS, even NS and FS reducing the BP reactivity.

\section{DISCUSSION}

The main findings of the present study were (a) the exercise session performed during the morning was more effective in



FIGURE 1 | Range of systolic blood pressure ( $\triangle \mathrm{SBP}$ ) in the postexercise moments. ${ }^{*} p \leq 0.05$ [morning session (MS) vs. control session (CS)]; ${ }^{*} p \leq 0.05$ [night session (NS) vs. CS)]; ${ }^{\circ} p \leq 0.05$ [MS vs. fractionized session (FS)].

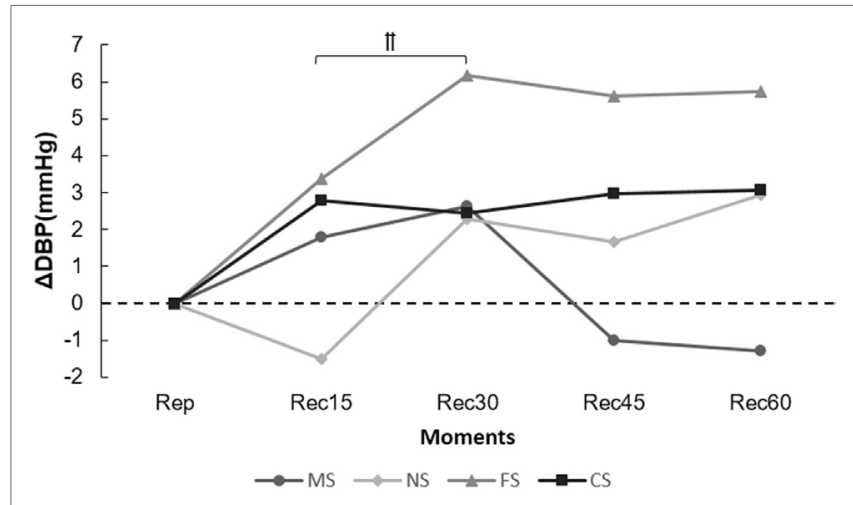

FIGURE 2 | Range of diastolic blood pressure ( $\triangle \mathrm{DBP}$ ) in the postexercise moments. ${ }^{\dagger \dagger} p \leq 0.05$ [Rec15 vs. Rec30 of night session (NS)]. promoting $\mathrm{PEH}$ for SBP than the other sessions; (b) the morning session was the only to promote attenuation of $\mathrm{BP}$ reactivity to SBP and DBP, compared to the CS; (c) the FS neither optimized $\mathrm{PEH}$ nor the attenuation of $\mathrm{BP}$ reactivity.

No differences were observed for the PEH for SBP between the MS and NS, yet de Brito et al. (32) observed higher PEH for SBP when 45 min of continuous AE session (50\% of $\mathrm{VO}_{2}$ peak) in pre-hypertensive was performed during the morning $(-7 \pm 3 \mathrm{mmHg})$ in relation to night $(-3 \pm 4 \mathrm{mmHg})$, on different days. Their finding may have occurred because these authors analyzed the effect of circadian rhythm on hemodynamic responses after continuous AE sessions in borderline hypertensive adults, unlike the present study, which aimed to investigate such effects in hypertensive middle-aged women after CE fractionized throughout the day.

The age and pathological condition of our volunteers as well as our exercise prescription may have influenced the results of the present study. The physiological changes caused by the aging process, the chronic presence of hypertension (55), and the influence caused by the pharmacological treatment (54) could reduce the statistical benefits of exercise for $\mathrm{BP}$. Moreover, it is also known that $\mathrm{PEH}$ is a multifactorial phenomenon, influenced by biological (e.g., sex, age, ethnicity, and genetics), behavior (e.g., excessive alcohol consumption, smoking, low levels of physical activity, and hyper sodic and hyper caloric diets), and socioeconomic (e.g., purchasing power and educational level) factors (56-59).

The results for DBP in the present study did not show reductions after exercise sessions. It can be associated with the methodological aspects adopted since an indirect and subjective method for controlling the intensity of aerobic session was used, which may be underestimated the desired exercise intensity (moderate to severe), although the scale used is a validated instrument (45) and the volunteers have undergone the familiarization process.

The findings of the present study contrast with our hypothesis, since some studies showed that AE sessions performed throughout the day (3-4 sessions of $10 \mathrm{~min}$ ) were associated with a better cardiovascular post-exercise response (14,35-39), and probably linked to greater release of vasoactive substances from endothelial cells. However, we investigated the BP kinetic after a $\mathrm{CE}$ protocol performed during the morning and the night of the same day. Therefore, the execution of two stimuli associated with the presence of the resistance component may have inhibited the $\mathrm{PEH}$ phenomenon in the present study.

TABLE 2 | Variation of systolic blood pressure (SBP), diastolic blood pressure (DBP), and mean arterial pressure after the CPT.

\begin{tabular}{|c|c|c|c|c|}
\hline & $\mathrm{CS}(\mathrm{mmHg})$ & $\begin{array}{c}M S(m m H g) \\
(\% \Delta)\end{array}$ & $\begin{array}{c}\text { NS }(\mathrm{mmHg}) \\
(\% \Delta)\end{array}$ & $\begin{array}{c}\mathrm{FS}(\mathrm{mmHg}) \\
(\% \Delta)\end{array}$ \\
\hline CPT (SBP) & 53.7 & $30.0(-44.2)^{\#}$ & $39.4(-26.6)$ & $39.5(-26.5)$ \\
\hline CPT (DBP) & 28.4 & $11.7(-58.8)^{\#}$ & $19.3(-32.1)$ & $22.4(-21.3)$ \\
\hline
\end{tabular}

CPT, cold pressure test; CS, control session; MS, morning session; NS, night session;

FS, fractionized session.

\#p $\leq 0.05$ (MS vs. CS).

$\% \Delta$ : in relation to CS values. 
Furthermore, it is also known that other variables can influence the magnitude and duration of $\mathrm{PEH}$, so understanding them is a key factor for the development of an effective physical exercise intervention. In this, some aspects can be highlighted as the ethnic and genetic factors (9), as well as the intensity (60), exercise volume (61), the type of recovery interval used between exercise series $(53,62,63)$, the muscle mass recruited (64), and the physical exercise modality $(18,30)$.

Additionally, Keese et al. (18) demonstrated that the intensity of aerobic component in $\mathrm{CE}$ can influence the $\mathrm{PEH}$, in which reported differences in the duration of the hypotensive effect to SBP after the sessions performed at 65 and $80 \%$ of $\mathrm{VO}_{2}$ peak compared to the session performed at $50 \%$ of $\mathrm{VO}_{2}$ peak in normotensive adults. Moreover, these authors demonstrated that the CE performed at 65 and $80 \%$ of $\mathrm{VO}_{2}$ peak was able to promote greater $\mathrm{PEH}$ for DBP $(\sim 1.8 \mathrm{mmHg})$ when compared to the CS performed at $50 \%$ of $\mathrm{VO}_{2}$ peak $(-1.2 \mathrm{mmHg})$, and the highest intensity session provided greater $\mathrm{PEH}$ duration to DBP than other intensities. This factor can be related by higher plasma kallikrein activity and increased bioavailability of the nitric oxide at the post-exercise period, promoting greater vasodilation and consequently higher $\mathrm{PEH}$ for the more intense session (65).

For the BP reactivity, the MS was better to attenuate the BP reactivity compared to the day without exercise. Analyzing the change on $\mathrm{BP}$ after the CPT between MS and CS $\left(\mathrm{MS}_{\mathrm{CPT}}-\mathrm{CS}_{\mathrm{CPT}}\right)$, there were significant differences of $-23.7 \pm 16.0$ and $-16.7 \pm 13.9 \mathrm{mmHg}$ for SBP and DBP, respectively. In agreement with these findings, Moreira et al. (7) showed a cardioprotection state after a circuited exercise session by attenuating the $\mathrm{BP}$ reactivity at $\sim 7 \mathrm{mmHg}$ for SBP and at $\sim 4 \mathrm{mmHg}$ for DBP in adults of both sexes.

Despite the fact that significant BP attenuation was not observed after FS and NS for SBP and DBP in the present study (Table 2), the variation's deltas in relation to CS were very high and, as previously discussed, it is extremely relevant as a cardioprotection effect. Considering the daily stress from nowadays and the physiological alterations related with hypertensive disease, all cardiovascular benefits obtained from these models of physical exercise are important.

All these data have great clinical and practical relevance, since sudden increases in BP favor the occurrence of some cardiovascular events, such as the rupture of atherosclerotic plaques, myocardial infarction, sudden cardiac death, and ischemic stroke (66). Complementary, Whelton et al. (17) showed that BP reductions of $5 \mathrm{mmHg}$ are sufficient to reduce by $14 \%$ the cases of stroke mortality, $9 \%$ of cases of coronary heart disease, and $7 \%$ the total risk of mortality caused by coronary heart disease.

The present study has some limitations such as (a) the nonbalance of volunteers by antihypertensive drug classes, such factor enables investigation, in fact, the interference of this variable in the PEH; (b) the non-utilization of a direct protocol for prescribing aerobic intensity; (c) the non-balance of the volunteers by the menopause stages, a feature that would allow analyzing the kinetic BP expressed from equivalent serum concentrations of estrogen hormones; (d) the non-standard regarding the drug administration schedule.
Despite the reported limitations, this study has high practical application, since most of the programs for control and treatment of hypertension, using physical exercise, concentrate their actions only in the aerobic component. Additionally, it is suggested that further studies based on the present proposal could be carried out, since due the daily duties, many people fail to practice physical activity for low availability of time, in this sense, the dissociation of a concurrent protocol seems to be an effective solution to maintain their health status preventing cardiovascular diseases. Moreover, applying new models of fractionated CEs to better understanding its cardiovascular benefits for hypertensive subjects must be investigated.

Additionally, the findings of the present study reinforce the security and benefits promoted by a physical exercise program performed following the American College of Sports Medicine (ACSM) guidelines, since significant acute reductions, as well as a cardioprotection state after the MS, were observed. It is important to highlight that the protocol adopted was performed around the inferior limit than suggested by ACSM (60-80\% of 1-RM), and it was still effective to promote benefits in hypertensive middleaged women.

In summary, the $\mathrm{CE}$ session proposed when performed in the morning is more effective for promoting $\mathrm{PEH}$ to SBP than the NS and FS, as well as showing greater attenuation of $\mathrm{BP}$ reactivity for SBP and DBP when compared to NS, FS, and CS in hypertensive middle-aged women. The NS also resulted some moments of $\mathrm{PEH}$ in relation to CS; however, there were no PEH for SBP after FS and for DBP after all sessions. Finally, the FS and NS provided good reductions, but not significant, for $\mathrm{BP}$ reactivity in relation to CS, with $\sim 40 \%$ of reduction for SBP and $\sim 20.5 \%$ of reduction for DBP.

\section{AUTHOR CONTRIBUTIONS}

LA, AS, and LS contributed to the design of the work, the acquisition, analysis, and interpretation of data, drafted the work; EP and JA contributed to the design of the work, the acquisition, analysis, and interpretation of data, drafted the work, and revisited it critically for important intellectual content; MF and RS contributed to the design of the work, the interpretation of data, revisited the work critically for important intellectual content. All authors approved the version to be published and agreed to be accountable for all aspects of the work in ensuring that questions related to the accuracy or integrity of any part of the work are appropriately investigated and resolved.

\section{FUNDING}

This work was supported by the State Agency to support Research and Technological Innovation of Sergipe (FAPITEC/SE).

\section{SUPPLEMENTARY MATERIAL}

The Supplementary Material for this article can be found online at http://journal.frontiersin.org/article/10.3389/fcvm.2017.00006/ full\#supplementary-material. 


\section{REFERENCES}

1. Ibrahim MM, Damasceno A. Hypertension in developing countries. Lancet (2012) 380:611-9. doi:10.1016/S0140-6736(12)60861-7

2. Lim SS, Vos T, Flaxman AD, Danaei G, Shibuya K, Adair-Rohani H, et al. A comparative risk assessment of burden of disease and injury attributable to 67 risk factors and risk factor clusters in 21 regions, 1990-2010: a systematic analysis for the Global Burden of Disease Study 2010. Lancet (2012) 380:2224-60. doi:10.1016/S0140-6736(12)61766-8

3. WHO. A Global Brief on Hypertension. Geneva: World Health Organization (2013).

4. Hills AP, Street SJ, Byrne NM. Physical activity and health: "what is old is new again”. Adv Food Nutr Res (2015) 75:77-95. doi:10.1016/bs.afnr.2015. 06.001

5. Cardoso CG, Gomides RS, Queiroz ACC, Pinto LG, da Silveira Lobo F, Tinucci T, et al. Acute and chronic effects of aerobic and resistance exercise on ambulatory blood pressure. Clinics (Sao Paulo) (2010) 65:317-25. doi:10.1590/S1807-59322010000300013

6. Cornelissen VA, Smart NA. Exercise training for blood pressure: a systematic review and meta-analysis. J Am Heart Assoc (2013) 2:e004473. doi:10.1161/ JAHA.112.004473

7. Moreira SR, Lima RM, Silva KES, Simões HG. Combined exercise circuit session acutely attenuates stress-induced blood pressure reactivity in healthy adults. Braz J Phys Ther (2014) 18:38-46. doi:10.1590/ S1413-35552012005000135

8. Lizardo JHF, Simões HG. Efeitos de diferentes sessões de exercícios resistidos sobre a hipotensao pós-exercício. Rev Bras Fisioter (2005) 9:289-95.

9. Pardono E, Almeida MB, Bastos A, Simões HG. Post-exercise hypotension: possible relationship with ethnic and genetic factors. Rev Bras Cineantropometria Desempenho Hum (2012) 14:353-61. doi:10.5007/1980-0037.2012v14n3p353

10. Halliwill JR. Mechanisms and clinical implications of post-exercise hypotension in humans. Exerc Sport Sci Rev (2001) 29:65-70. doi:10.1097/00003677-200104000-00005

11. Kenney MJ, Seals DR. Postexercise hypotension. Key features, mechanisms, and clinical significance. Hypertension (1993) 22:653-64. doi:10.1161/01. HYP.22.5.653

12. Pescatello LS, Franklin BA, Fagard R, Farquhar WB, Kelley GA, Ray CA. American College of Sports Medicine position stand. Exercise and hypertension. Med Sci Sport Exerc (2004) 36:533-53. doi:10.1249/01. MSS.0000115224.88514.3A

13. Pardono E, Fernandes M, Azevêdo LM, Almeida JA, Mota MR, Simões HG. Post-exercise hypotension of normotensive young men through track running sessions. Rev Bras Med do Esporte (2015) 21:192-5. doi:10.1590/1517-869220152103137534

14. Bhammar DM, Angadi SS, Gaesser GA. Effects of fractionized and continuous exercise on 24-h ambulatory blood pressure. Med Sci Sports Exerc (2012) 44:2270-6. doi:10.1249/MSS.0b013e3182663117

15. Cunha GA, da Rios ACS, Moreno JR, Braga PL, Campbell CSG, Simões HG, et al. Hipotensão pós-exercício em hipertensos submetidos ao exercício aeróbio de intensidades variadas e exercício de intensidade constante. Rev Bras Med Esporte (2006) 12:313-7. doi:10.1590/S1517-86922006000600003

16. Quinn TJ. Twenty-four hour, ambulatory blood pressure responses following acute exercise: impact of exercise intensity. J Hum Hypertens (2000) 14:547-53. doi:10.1038/sj.jhh.1001106

17. Whelton PK, He J, Appel LJ, Cutler JA, Havas S, Kotchen TA, et al. Primary prevention of hypertension: clinical and public health advisory from The National High Blood Pressure Education Program. JAMA (2002) 288:1882-8. doi:10.1001/jama.288.15.1882

18. Keese F, Farinatti P, Pescatello L, Monteiro W. A comparison of the immediate effects of resistance, aerobic, and concurrent exercise on postexercise hypotension. J Strength Cond Res (2011) 25:1429-36. doi:10.1519/ JSC.0b013e3181d6d968

19. Pescatello LS, MacDonald HV, Ash GI, Lamberti LM, Farquhar WB, Arena $\mathrm{R}$, et al. Assessing the existing professional exercise recommendations for hypertension: a review and recommendations for future research priorities. Mayo Clin Proc (2015) 90:801-12. doi:10.1016/j.mayocp.2015.04.008

20. Pescatello LS, MacDonald HV, Lamberti L, Johnson BT. Exercise for hypertension: a prescription update integrating existing recommendations with emerging research. Curr Hypertens Rep (2015) 17:87. doi:10.1007/ s11906-015-0600-y

21. Leveritt M, Abernethy PJ, Barry B, Logan PA. Concurrent strength and endurance training: the influence of dependent variable selection. J Strength Cond Res (2003) 17:503-8. doi:10.1519/00124278-200308000-00013

22. Dos Santos ES, Asano RY, Filho IG, Lopes NL, Panelli P, Nascimento D, et al. Acute and chronic cardiovascular response to 16 weeks of combined eccentric or traditional resistance and aerobic training in elderly hypertensive women: a randomized controlled trial. J Strength Cond Res (2014) 28:3073-84. doi:10.1519/JSC.0000000000000537

23. Guirado GN, Damatto RL, Matsubara BB, Roscani MG, Fusco DR, Cicchetto LAF, et al. Combined exercise training in asymptomatic elderly with controlled hypertension: effects on functional capacity and cardiac diastolic function. Med Sci Monit (2012) 18:CR461-5. doi:10.12659/MSM.883215

24. Keese F, Farinatti P, Pescatello L, Cunha FA, Monteiro WD. Aerobic exercise intensity influences hypotension following concurrent exercise sessions. Int J Sports Med (2012) 33:148-53. doi:10.1055/s-0031-1291321

25. Menêses AL, Forjaz CL, de Lima PFM, Batista RMF, Monteiro M, Ritti-Dias RM. Influence of endurance and resistance exercise order on the postexercise hemodynamic responses in hypertensive women. J Strength Cond Res (2015) 29:612-8. doi:10.1519/JSC.0000000000000676

26. Ruiz RJ, Simão R, Saccomani MG, Casonatto J, Alexander JL, Rhea M, et al. Isolated and combined effects of aerobic and strength exercise on post-exercise blood pressure and cardiac vagal reactivation in normotensive men. J Strength Cond Res (2011) 25:640-5. doi:10.1519/JSC.0b013e3181c1fcc7

27. Sousa N, Mendes R, Abrantes C, Sampaio J, Oliveira J. A randomized 9-month study of blood pressure and body fat responses to aerobic training versus combined aerobic and resistance training in older men. Exp Gerontol (2013) 48:727-33. doi:10.1016/j.exger.2013.04.008

28. Stewart KJ, Bacher AC, Turner KL, Fleg JL, Hees PS, Shapiro EP, et al. Effect of exercise on blood pressure in older persons: a randomized controlled trial. Arch Intern Med (2005) 165:756-62. doi:10.1001/archinte.165.7.756

29. Tan S, Li W, Wang J. Effects of six months of combined aerobic and resistance training for elderly patients with a long history of type 2 diabetes. $J$ Sports Sci Med (2012) 11:495-501.

30. Teixeira L, Ritti-Dias RM, Tinucci T, Mion Júnior D, Forjaz CL. Postconcurrent exercise hemodynamics and cardiac autonomic modulation. Eur J Appl Physiol (2011) 111:2069-78. doi:10.1007/s00421-010-1811-1

31. Brito LC, Queiroz ACC, Forjaz CLM. Influence of population and exercise protocol characteristics on hemodynamic determinants of post-aerobic exercise hypotension. Braz J Med Biol Res (2014) 47:626-36. doi:10.1590/1414-431X20143832

32. de Brito LC, Rezende RA, da Silva Junior ND, Tinucci T, Casarini DE, Cipolla-Neto J, et al. Post-exercise hypotension and its mechanisms differ after morning and evening exercise: a randomized crossover study. PLoS One (2015) 10:e0132458. doi:10.1371/journal.pone.0132458

33. Jones H, George K, Edwards B, Atkinson G. Effects of time of day on post-exercise blood pressure: circadian or sleep-related influences? Chronobiol Int (2008) 25:987-98. doi:10.1080/07420520802548044

34. Jones H, Pritchard C, George K, Edwards B, Atkinson G. The acute post-exercise response of blood pressure varies with time of day. Eur J Appl Physiol (2008) 104:481-9. doi:10.1007/s00421-008-0797-4

35. Angadi SS, Weltman A, Watson-Winfield D, Weltman J, Frick K, Patrie J, et al. Effect of fractionized vs continuous, single-session exercise on blood pressure in adults. J Hum Hypertens (2010) 24:300-2. doi:10.1038/jhh.2009.110

36. Miyashita M, Burns SF, Stensel DJ. Accumulating short bouts of running reduces resting blood pressure in young normotensive/pre-hypertensive men. J Sports Sci (2011) 29:1473-82. doi:10.1080/02640414.2011.593042

37. Padilla J, Wallace JP, Park S. Accumulation of physical activity reduces blood pressure in pre- and hypertension. Med Sci Sports Exerc (2005) 37:1264-75. doi:10.1249/01.mss.0000175079.23850.95

38. Park S, Rink L, Wallace J. Accumulation of physical activity: blood pressure reduction between 10-min walking sessions. J Hum Hypertens (2008) 22:475-82. doi:10.1038/jhh.2008.29

39. Park S, Rink LD, Wallace JP. Accumulation of physical activity leads to a greater blood pressure reduction than a single continuous session, in prehypertension. J Hypertens (2006) 24:1761-70. doi:10.1097/01. hjh.0000242400.37967.54 
40. Evans SM, Griffiths RR. Caffeine withdrawal: a parametric analysis of caffeine dosing conditions. J Pharmacol Exp Ther (1999) 289:285-94.

41. Juliano LM, Huntley ED, Harrell PT, Westerman AT. Development of the caffeine withdrawal symptom questionnaire: caffeine withdrawal symptoms cluster into 7 factors. Drug Alcohol Depend (2012) 124:229-34. doi:10.1016/j. drugalcdep.2012.01.009

42. Meredith SE, Juliano LM, Hughes JR, Griffiths RR. Caffeine use disorder: a comprehensive review and research agenda. J Caffeine Res (2013) 3:114-30. doi:10.1089/jcr.2013.0016

43. Harriss DJ, Atkinson G. Ethical standards in sport and exercise science research: 2014 update. Int J Sports Med (2013) 34:1025-8. doi:10.1055/ s-0033-1358756

44. WHO. Waist Circumference and Waist-Hhip Ratio: Report of a WHO Expert Consultation. Geneva: World Health Organization (2011). 39 p.

45. Da Silva-Grigoletto ME, Viana-Montaner BH, Heredia JR, Mata F, Peña G, Brito CJ, et al. Validación de la escala de valoración subjetiva del esfuerzo OMNI-GSE para el control de la intensidad global en sesiones de objetivos múltiples en personas mayores. Kronos (2013) 12:32-40.

46. Amarante do Nascimento M, Januário RSB, Gerage AM, Mayhew JL, Cheche Pina FL, Cyrino ES. Familiarization and reliability of one repetition maximum strength testing in older women. J Strength Cond Res (2013) 27:1636-42. doi:10.1519/JSC.0b013e3182717318

47. Phillips WT, Batterham AM, Valenzuela JE, Burkett LN. Reliability of maximal strength testing in older adults. Arch Phys Med Rehabil (2004) 85:329-34. doi:10.1016/j.apmr.2003.05.010

48. Taylor JD, Fletcher JP. Reliability of the 8-repetition maximum test in men and women. J Sci Med Sport (2012) 15:69-73. doi:10.1016/j.jsams.2011. 07.002

49. Dias RMR, Avelar A, Menêses AL, Salvador EP, Da Silva DRP, Cyrino ES. Segurança, reprodutibilidade, fatores intervenientes e aplicabilidade de testes de 1-RM. Motriz Rev Educ Fis (2013) 19:231-42. doi:10.1590/ S1980-65742013000100024

50. Topouchian JA, El Assaad MA, Orobinskaia LV, El Feghali RN, Asmar RG. Validation of two devices for self-measurement of brachial blood pressure according to the International Protocol of the European Society of Hypertension: the SEINEX SE-9400 and the Microlife BP 3AC1-1. Blood Press Monit (2005) 10:325-31. doi:10.1097/00126097-20051200000008

51. Cortez-Cooper MY, Anton MM, Devan AE, Neidre DB, Cook JN, Tanaka $\mathrm{H}$. The effects of strength training on central arterial compliance in middle-aged and older adults. Eur J Cardiovasc Prev Rehabil (2008) 15:149-55. doi:10.1097/HJR.0b013e3282f02fe2

52. Hines EA, Brown GE. The cold pressor test for measuring the reactibility of the blood pressure: data concerning 571 normal and hypertensive subjects. Am Heart J (1936) 11:1-9. doi:10.1016/S0002-8703(36)90370-8

53. Brito AF, Alves NF, Araújo AS, Goncalves MC, Silva AS. Active intervals between sets of resistance exercises potentiate the magnitude of postexercise hypotension in elderly hypertensive women. J Strength Cond Res (2011) 25:3129-36. doi:10.1519/JSC.0b013e318212dd25

54. Webb AJS, Fischer U, Mehta Z, Rothwell PM. Effects of antihypertensive-drug class on interindividual variation in blood pressure and risk of stroke: a systematic review and meta-analysis. Lancet (2010) 375:906-15. doi:10.1016/ S0140-6736(10)60235-8
55. Barac A, Panza JA. Mechanisms of decreased vascular function with aging. Hypertension (2009) 53:900-2. doi:10.1161/HYPERTENSIONAHA. 109.132308

56. Keusch S, Hildenbrand FF, Bollmann T, Halank M, Held M, Kaiser R, et al. Tobacco smoke exposure in pulmonary arterial and thromboembolic pulmonary hypertension. Respiration (2014) 88:38-45. doi:10.1159/000359972

57. O'Keefe JH, Bybee KA, Lavie CJ. Alcohol and cardiovascular health: the razor-sharp double-edged sword. J Am Coll Cardiol (2007) 50:1009-14. doi:10.1016/j.jacc.2007.04.089

58. Perin MS, Cornélio ME, Rodrigues RCM, Gallani MCBJ. Caracterização do consumo de sal entre hipertensos segundo fatores sociodemográficos e clínicos. Rev Lat Am Enfermagem (2013) 21:1-9.

59. Wang B, Liao C, Zhou B, Cao W, Lv J, Yu C, et al. Genetic contribution to the variance of blood pressure and heart rate: a systematic review and meta-regression of twin studies. Twin Res Hum Genet (2015) 18:158-70. doi:10.1017/thg. 2015.8

60. Pescatello LS, Guidry MA, Blanchard BE, Kerr A, Taylor AL, Johnson AN, et al. Exercise intensity alters postexercise hypotension. J Hypertens (2004) 22:1881-8. doi:10.1097/00004872-200410000-00009

61. Anunciação PG, Poton R, Szytko A, Polito MD. Comportamento cardiovascular após o exercício resistido realizado de diferentes formas e volumes de trabalho. Rev Bras Med do Esporte (2012) 18:117-21. doi:10.1590/ S1517-86922012000200011

62. Abrahin O, Rodrigues RP, Ramos AM, da Silva-Grigoletto ME, Pardono E, Marçal AC. Active intervals during high-intensity resistance exercises enhance post-exercise hypotension in hypertensive women controlled by medications. Isokinet Exerc Sci (2016) 24:141-7. doi:10.3233/IES-160611

63. de Salles BF, Maior AS, Polito M, Novaes J, Alexander J, Rhea M, et al. Influence of rest interval lengths on hypotensive response after strength training sessions performed by older men. J Strength Cond Res (2010) 24:3049-54. doi:10.1519/JSC.0b013e3181ddb207

64. Polito MD, Farinatti PTV. The effects of muscle mass and number of sets during resistance exercise on postexercise hypotension. J Strength Cond Res (2009) 23:2351-7. doi:10.1519/JSC.0b013e3181bb71aa

65. Motta DF, Lima LCJ, Arsa G, Russo PS, Sales MM, Moreira SR, et al. Effect of type 2 diabetes on plasma kallikrein activity after physical exercise and its relationship to post-exercise hypotension. Diabetes Metab (2010) 36:363-8. doi:10.1016/j.diabet.2010.03.008

66. Muller JE, Tofler GH, Stone PH. Circadian variation and triggers of onset of acute cardiovascular disease. Circulation (1989) 79:733-43. doi:10.1161/01. CIR.79.4.733

Conflict of Interest Statement: The authors declare that the research was conducted in the absence of any commercial or financial relationships that could be construed as a potential conflict of interest.

Copyright $\odot 2017$ Azevêdo, Souza, Santos, Miguel dos Santos, Fernandes, Almeida and Pardono. This is an open-access article distributed under the terms of the Creative Commons Attribution License (CC BY). The use, distribution or reproduction in other forums is permitted, provided the original author(s) or licensor are credited and that the original publication in this journal is cited, in accordance with accepted academic practice. No use, distribution or reproduction is permitted which does not comply with these terms. 